\title{
Research Article \\ Effect of Curing Temperature Histories on the Compressive Strength Development of High-Strength Concrete
}

\author{
Keun-Hyeok Yang, ${ }^{1}$ Jae-Sung Mun, ${ }^{2}$ and Myung-Sug $\mathrm{Cho}^{3}$ \\ ${ }^{1}$ Department of Plant \& Architectural Engineering, Kyonggi University, Suwon, Gyonggi-do 443-760, Republic of Korea \\ ${ }^{2}$ Department of Architectural Engineering, Graduate School, Kyonggi University, Suwon, Gyonggi-do 443-760, Republic of Korea \\ ${ }^{3}$ Central Research Institute, Korea Hydro \& Nuclear Power Co., Ltd. (KHNP), Daejeon 305-343, Republic of Korea
}

Correspondence should be addressed to Keun-Hyeok Yang; yangkh@kgu.ac.kr

Received 18 January 2015; Revised 7 May 2015; Accepted 10 May 2015

Academic Editor: Wenbin Yi

Copyright ( 2015 Keun-Hyeok Yang et al. This is an open access article distributed under the Creative Commons Attribution License, which permits unrestricted use, distribution, and reproduction in any medium, provided the original work is properly cited.

\begin{abstract}
This study examined the relative strength-maturity relationship of high-strength concrete (HSC) specifically developed for nuclear facility structures while considering the economic efficiency and durability of the concrete. Two types of mixture proportions with water-to-binder ratios of 0.4 and 0.28 were tested under different temperature histories including (1) isothermal curing conditions of $5^{\circ} \mathrm{C}, 20^{\circ} \mathrm{C}$, and $40^{\circ} \mathrm{C}$ and (2) terraced temperature histories of $20^{\circ} \mathrm{C}$ for an initial age of individual 1,3 , or 7 days and a constant temperature of $5^{\circ} \mathrm{C}$ for the subsequent ages. On the basis of the test results, the traditional maturity function of an equivalent age was modified to consider the offset maturity and the insignificance of subsequent curing temperature after an age of 3 days on later strength of concrete. To determine the key parameters in the maturity function, the setting behavior, apparent activation energy, and rate constant of the prepared mixtures were also measured. This study reveals that the compressive strength development of HSC cured at the reference temperature for an early age of 3 days is insignificantly affected by the subsequent curing temperature histories. The proposed maturity approach with the modified equivalent age accurately predicts the strength development of HSC.
\end{abstract}

\section{Introduction}

There has been an increasing interest in the practical application of high-strength concrete (HSC) in the fast-track construction of nuclear facility structures with a prestress system. As demonstrated by several studies $[1,2]$ accelerated construction schedules of structures can be achieved by using HSC because of its naturally high early-age strength gain compared to normal-strength concrete (NSC). Therefore, the accurate evaluation of the early-age in-place properties of HSC is important for determining the following construction phases [2]: (1) the minimum stripping time of the concrete form and shoring; (2) the minimum concrete age for applying prestressing force to a structural element; and (3) the temperature and the length of time for accelerated in situ curing processes, particularly in cold weather. Furthermore, the effect of initial curing temperature on the strength development of concrete over the long term must be carefully examined because the long-term strength affects the remodeling and durability of concrete structures. The in-place strength gain of concrete under various temperature conditions is commonly traced using the maturity-strength relationship $[3,4]$. However, most of the existing relationships [3-11] between maturity function and strength development have been derived from NSC data and verified using such data. Moreover, much less maturity data are available for HSC $[2,12]$ than for NSC.

The concept of maturity is used to describe the combined effect of temperature and age on concrete strength development. However, the accuracy and feasibility of maturitystrength relationship remain controversial because of a lack of scientific consensus on the compatibility between maturity and hydration kinetics of cement [12]. The concept of equivalent age derived from the Arrhenius function [13] has been primarily used as a maturity function to describe the temperature sensitivity of the reaction of cementitious materials. In recent years, to explain the crossover effect and accurately 
predict the long-term strength of in-place concrete, the specific relationship between the degree of hydration and the relative strength ratio has been introduced into the Arrhenius function [3-7]. Traditionally, the apparent activation energy and/or rate constant for a given concrete are considered as key parameters in a maturity function based on equivalent age. Several researchers $[4,5]$ have proposed simple equations to determine the apparent activation energy using regression analysis of the experimental data for NSC. However, further experimental verification is needed to extend those equations to HSC, because the activation energy depends significantly on the rate of hydration degree which is affected by the water-to-binder ratio and the dosage of supplementary cementitious materials (SCMs).

The objective of the present study was to evaluate the maturity-strength relationship in HSC. Mixture proportions of HSC were specifically determined for its use in nuclear facility structures, while considering the economic efficiency and durability of concrete. Two types of mixture proportions with design strengths of $42 \mathrm{MPa}$ and $65 \mathrm{MPa}$ were tested under different temperature histories as follows: (1) isothermal curing conditions of $5^{\circ} \mathrm{C}, 20^{\circ} \mathrm{C}$, and $40^{\circ} \mathrm{C}$ and (2) terraced temperature histories of $20^{\circ} \mathrm{C}$ for an initial age of individual 1,3 , or 7 days and a constant temperature of $5^{\circ} \mathrm{C}$ for the subsequent ages. The setting behavior, apparent activation energy, and rate constant of both prepared mixtures were also measured in accordance with ASTM procedures [14]. The maturity approach proposed by Carino and Tank [3] was modified to consider the effect of curing temperature at an early age on the later strength gain of the concrete. The modified version adopts the strength ratio relative to 28-day strength, temperature until an age of 3 days, and the hydration-degree-dependent apparent activation energy at the hardening phase. To estimate the compressive strength at various ages from the proposed relative strength-maturity relationship, a simple equation for straightforward prediction of the 28-day strength was formulated using the test results.

\section{Maturity Approach}

On the basis of a review of previously described relationships $[3,8,14,15]$ between maturity function and strength, the basic formula proposed by Carino and Tank [3] was modified to attain the present maturity approach. For the same value of the maturity index, most concrete mixtures exhibit crossover behavior, that is, higher early-age temperatures result in higher early strength and lower long-term strength, as shown in Figure 1. A given concrete mixture does not possess a unique strength-maturity relationship. This indicates that the maturity function is related to the relative strength ratio rather than to absolute strength and that the activation energy for a given concrete needs to be evaluated according to the maturity. The offset time for introducing the induction period before rapid strength development is also sensitive to temperature. The present maturity approach adopts the strength ratio relative to 28-day strength and the hydration-degreedependent apparent activation energy at the hardening phase. The maturity function is identified using the equivalent age including offset and hardening phases.

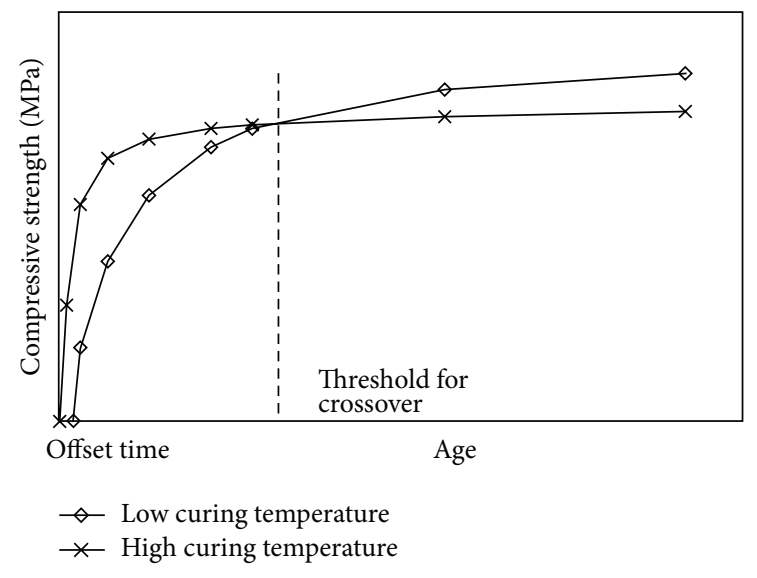

FIGURE 1: Crossover effect during strength development of concrete due to different curing temperature.

2.1. Relative Strength Development. Under isothermal curing, the compressive strength $(S)$ of concrete at age $t$ (in days) is commonly determined from the following hyperbolic function:

$$
S=\frac{k_{T}\left(t-t_{0}\right)}{1+k_{T}\left(t-t_{0}\right)} S_{u}
$$

where $k_{T}$ is the rate constant (in units of day ${ }^{-1}$ ) for strength development at the curing temperature, $t_{0}$ is the offset time (in days) indicating the age at which strength development is assumed to begin, and $S_{u}$ is the limiting strength. In evaluating limiting strength at an infinite age, $t_{0}$ is negligible. Thus, (1) can be rewritten in terms of 28-day compressive strength $\left(S_{28}\right)$ as follows:

$$
\begin{gathered}
\frac{S}{S_{28}}=\beta_{1} \frac{k_{T}\left(t-t_{0}\right)}{1+k_{T}\left(t-t_{0}\right)} \\
\beta_{1}=\frac{S_{u}}{S_{28}}=1+\frac{1}{k_{T} \cdot 28} .
\end{gathered}
$$

Maturity represents the curing age at a fixed reference temperature necessary to achieve the same level of maturity when cured at a different temperature history. Therefore, in terms of equivalent age $\left(t_{e}\right)$, (2) can be rewritten to describe the relative strength-maturity relationship $[3,15]$ :

$$
\frac{S}{S_{28}}=\beta_{1} \frac{k_{r}\left(t_{e}-t_{0 r}\right)}{1+k_{r}\left(t_{e}-t_{0 r}\right)}
$$

where $k_{r}$ and $t_{0 r}$ are the rate constant and offset time, respectively, at the reference temperature.

2.2. Equivalent Age and Offset Time. Because the rate constant is related to the rate of strength gain at a given age, the variation of the rate constant with curing temperature should be determined for a reliable maturity function of a given concrete mixture. The rate constant function is generally expressed using the Arrhenius function [13] as follows:

$$
k_{T}=A \cdot \exp \left[\frac{-E_{a}}{R(T+273)}\right] \text {, }
$$


where $A$ is the experimental constant (in day ${ }^{-1}$ ), $E_{a}$ is the apparent activation energy (in $\mathrm{J} / \mathrm{mol}), A(=8.314 \mathrm{~J} / \mathrm{mol} \cdot \mathrm{K})$ is the universal gas constant, and $T$ is the curing temperature (in ${ }^{\circ} \mathrm{C}$ ). According to the maturity principle, the equivalent age at hardening phase $\left(t_{\mathrm{eh}}\right)$ can be written as follows [3]:

$$
\begin{aligned}
t_{\mathrm{eh}} & =\sum_{t_{0}}^{t}\left(\frac{k_{T}}{k_{r}}\right) \Delta t \\
& =\sum_{t_{0}}^{t} \exp \left[\frac{-E_{a}}{R}\left(\frac{1}{T+273}-\frac{1}{T_{r}+273}\right)\right] \Delta t,
\end{aligned}
$$

where $T_{r}$ is the reference temperature (in ${ }^{\circ} \mathrm{C}$ ). Note that $k_{T} / k_{r}$ in (6) denotes an age conversion factor that is defined as an affinity ratio $(\gamma)$ of the rate constants at the hardening phase. From (6), the factor $k_{T}$ used to calculate the value of $\beta_{1}$ can be expressed in the following form:

$$
k_{T}=k_{r} \exp \left[\frac{-E_{a}}{R}\left(\frac{1}{T+273}-\frac{1}{T_{r}+273}\right)\right] .
$$

The offset time $\left(t_{0 r}\right)$ at the reference temperature is related to the setting behavior of a given concrete. Whereas the equivalent age at the hardening phase to achieve the same fraction of the limiting strength at different temperatures is proportional to the affinity ratio, the offset time at the setting phase is inversely proportional to the affinity ratio, because the higher the temperature, the faster is the setting time. For this reason, Pinto and Hover [16] pointed out that the apparent activation energy for the period up to initial and final set can be estimated from an Arrhenius plot using $\ln \left(1 / t_{i}\right)$ instead of $\ln \left(k_{t}\right)$, where $t_{i}$ is the setting time. The exact point of offset time $\left(t_{0}\right)$ at a given temperature remains uncertain because of various factors including unit binder content, the water-to-binder ratio $(W / B)$, and the types and the amounts of added SCMs and chemical agents. However, several studies $[3,15,16]$ conclude that $t_{0}$ is close to the final setting time $\left(t_{s}\right)$ of concrete at a given temperature. Pinto and Schindler [15] also pointed out that the selection of $t_{s}$ for $t_{0}$ does not significantly affect the prediction of the in-place strength of concrete. On the basis of the existing conclusions, the present study assumes that $t_{0}$ is equal to $t_{s}$. Therefore, from the Arrhenius function, $t_{0 r}$ can be simply expressed as follows:

$$
\begin{aligned}
t_{0 r} & =\sum_{0}^{t_{s r}}\left(\frac{k_{s r}}{k_{s T}}\right) \Delta t \\
& =t_{s r} \exp \left[\frac{-E_{s}}{R}\left(\frac{1}{T+273}-\frac{1}{T_{r}+273}\right)\right],
\end{aligned}
$$

where $t_{s r}$ is the final setting time of concrete at the reference temperature, $k_{s r}$ and $k_{s T}$ are the rate constants for the setting development at the reference temperature and a different temperature, respectively, and $E_{s}$ is the apparent activation energy until final setting time. Overall, taking into consideration of the setting and hardening phases, the equivalent age $\left(t_{e}\right)$ in (4) can then be obtained from

$$
\begin{aligned}
t_{e}= & \sum_{0}^{t_{s r}} \exp \left[\frac{-E_{s}}{R}\left(\frac{1}{T+273}-\frac{1}{T_{r}+273}\right)\right] \Delta t \\
& +\sum_{t_{s r}}^{t} \exp \left[\frac{-E_{a}}{R}\left(\frac{1}{T+273}-\frac{1}{T_{r}+273}\right)\right] \Delta t .
\end{aligned}
$$

2.3. Activation Energy at Hardening Phase. It is commonly known [17] that cement with conventional fineness would not hydrate completely at normal $W / B$, even at ages exceeding 100 years. Cha [17] demonstrated that the degree of hydration according to age can be generally characterized as a parabola converging toward an ultimate value. This indicates that curing temperature plays an important role in the rate of hydration degree at early age whereas its effect becomes minimal at long-term age because the hydration reaction gradually reaches a stable state with age. This temperature-dependent hydration reaction also affects the value of the activation energy $\left(E_{a}\right)$ at the hardening phase. Byfors [18] showed that $E_{a}$ decreases sharply beyond a certain age that varies with curing temperature. Therefore, it is expected that $E_{a}$ somewhat depends on the curing temperature and age. The present study uses the following simple model empirically fitted by Kim et al. [19] to estimate $E_{a}$ according to age and temperature:

$$
E_{a}=E_{i} \cdot \exp (-0.00017 T \cdot t),
$$

where $E_{i}$ is the initial apparent activation energy at the hardening phase.

2.4. Determination of Key Parameters. In the abovementioned maturity approach to predict the in-place strength development of concrete mixed in given proportions, several key parameters such as $t_{s r}, k_{r}, E_{i}$, and $E_{s}$ must be provided. To minimize the margin of error in predicting the in-place strength of the concrete, it is desirable that these parameters for a given concrete are determined on the basis of an appropriate experimental program. The value of $E_{i}$ can be determined from the slope of the best-fitting line of data plotted in the natural logarithm of $k_{T}$ values versus temperatures, in accordance with ASTM [14]. The value of $E_{s}$ can be determined from the Arrhenius plot using the inverse of final setting times instead of the rate constant [16]. The values of $t_{s r}$ and $k_{r}$ can be directly obtained from concrete specimens cured at the reference temperature. In predicting in-place strength using the relative strength-maturity relationship, it is sometimes impractical to use $S_{28}$ measured in laboratory tests to represent an actual value in situ. Standard concrete specimens are usually cured and tested under ideal conditions with a constant room temperature. However, concrete structures are exposed to external environment in service. This is why it is not easy to fit the laboratory curing temperature to the in situ condition over wide ranges [20-22]. Therefore, for practical and straightforward application of the maturity 
TABLE 1: Details of concrete mixture proportions.

\begin{tabular}{lcccccccc}
\hline Type & \multirow{2}{*}{ Design strength $(\mathrm{MPa})$} & \multirow{2}{*}{ W/B } & Water & Cement & Silica fume & Sand & Gravel & $R_{\mathrm{sp}}{ }^{*}(\%)$ \\
\hline I & 42 & 0.4 & 155 & 368 & 19.4 & 763 & 973 \\
II & 65 & 0.28 & 155 & 526 & 27.7 & 701 & 895 & 2.0 \\
\hline
\end{tabular}

${ }^{*} R_{\mathrm{sp}}=$ high-range water-reducing agent-to-binder ratio by weight.

TABLE 2: Chemical composition of cementitious materials (\% by mass).

\begin{tabular}{lcccccccccc}
\hline Materials & $\mathrm{SiO}_{2}$ & $\mathrm{Al}_{2} \mathrm{O}_{3}$ & $\mathrm{Fe}_{2} \mathrm{O}_{3}$ & $\mathrm{CaO}$ & $\mathrm{MgO}$ & $\mathrm{K}_{2} \mathrm{O}$ & $\mathrm{Na}_{2} \mathrm{O}$ & $\mathrm{TiO}_{2}$ & $\mathrm{SO}_{3}$ & $\mathrm{LOI}^{*}$ \\
\hline OPC & 23.30 & 3.85 & 3.83 & 63.4 & 1.24 & 1.47 & 0.15 & 0.33 & 2.01 \\
$\mathrm{SF}$ & 98.94 & 0.30 & 0.08 & 0.12 & 0.04 & 0.13 & 0.05 & - & 0.42 \\
\hline
\end{tabular}

${ }^{*}$ Loss on ignition.

approach to predict in-place strength of concrete at various ages, the relationship between $S_{28}$ and $\left(S_{28}\right)_{T_{r}}$ should ideally be established for a given concrete, where $\left(S_{28}\right)_{T_{r}}$ is the 28day compressive strength of concrete cured at the reference temperature.

\section{Experimental Details}

3.1. Concrete Specimens. Two types of concrete mixture proportions were prepared, as listed in Table 1. Under the conventional curing conditions of a constant temperature and relative humidity of $20^{\circ} \mathrm{C}$ and $60 \%$, respectively, the design compressive strength of concrete was $42 \mathrm{MPa}$ and $65 \mathrm{MPa}$ for type I and II mixtures, respectively. The proportions for both concrete mixtures were determined in numerous laboratory tests for practical application to nuclear facility structures. The $W / B$ for type I and type II mixtures were selected as 0.4 and 0.28 , respectively.

The cement that is commonly used for nuclear plant structures in South Korea was selected as the main binder. The chemical composition of the cement was specially modified to reduce the hydration heat. As a result, the chemical composition of the cement was close to that of moderate heat cement, as listed in Table 2. As compared with the common chemical composition of ordinary Portland cement (OPC), the aluminum oxide $\left(\mathrm{Al}_{2} \mathrm{O}_{3}\right)$ content in the modified cement was lower by approximately $2 \%$, whereas the silicon oxide $\left(\mathrm{SiO}_{2}\right)$ content was $1 \%$ higher. A calculation of the mineral compositions based on the chemical composition showed that the $\mathrm{C}_{3} \mathrm{~S}$ and $\mathrm{C}_{3} \mathrm{~A}$ contents of the modified cement were $16 \%$ and $54 \%$ lower than those of OPC, respectively, whereas $\mathrm{C}_{2} \mathrm{~S}$ content of the former was $37.6 \%$ higher than that of latter. The primary component of the silica fume (SF) was $\mathrm{SiO}_{2}$. The specific gravity and specific surface area of the used cementitious materials were 3.15 and $3466 \mathrm{~cm}^{2} / \mathrm{g}$ for cement and 2.32 and $200000 \mathrm{~cm}^{2} / \mathrm{g}$ for SF, respectively.

Mixing and specimen preparation were conducted at room temperature of $20 \pm 2^{\circ} \mathrm{C}$. Fine and coarse aggregates together with the preblended binder were dry-mixed in a $0.35 \mathrm{~m}^{3}$ capacity mixer pan for $1 \mathrm{~min}$ and then wet-mixed for a further $1 \mathrm{~min}$. Immediately after casting, all specimens were covered with a plastic sheet to prevent the hydration water from evaporating and transferred to a temperaturecontrolled chamber.

3.2. Curing Process. The average curing temperatures in each chamber were previously set to $5^{\circ} \mathrm{C}, 20^{\circ} \mathrm{C}$, and $40^{\circ} \mathrm{C}$ to simulate winter (cold), controlled laboratory (reference), and summer (hot) conditions, respectively. For each concrete mixture type, curing temperature histories were classified into two regimes: isothermal and terrace-shaped variable conditions. Thus, specimen notation was identified according to the mixture type and temperature regime, as listed in Table 3. Specimens under the isothermal condition were continuously cured in the previously set chamber until the time of testing. Specimens under terraced temperature histories were designed to estimate the age at which there would be $80 \%$ gain of 28 -day compressive strength, which corresponds to the removal time of the concrete form for nuclear facility structures in cold weather. In the terraced temperature histories, the initial periods at the reference temperature were selected as 1, 3, and 7 days, and subsequent temperature was maintained at $5^{\circ} \mathrm{C}$. Therefore, specimens under terraced temperature histories were initially cured in the reference chamber until the specified age for testing and then transferred to the cold chamber.

3.3. Testing. Real-time curing temperatures were monitored at the center of the specimens and the environmental chamber using thermocouples and saved automatically in a data logger. To determine the temperature-sensitive factor and apparent activation energy of the concrete at setting phase, fresh mortar was extracted from the concrete with a $4.75 \mathrm{~mm}$ sieve screening. The penetration resistance testing to examine the setting behavior of concrete was conducted in accordance with ASTM [14]. The testing required to determine experimentally the apparent activation energy at the hardening phase was performed using 18 cubes with $50 \mathrm{~mm}$ dimensions per isothermal curing history, in accordance with ASTM [14]. The measurement of the compressive strength of concrete was scheduled at the ages of $1,3,7,13,22,28,56$, and 91 days using a $100 \times 200 \mathrm{~mm}$ cylinder. However, testing compressive strength of specimen I-C at age of one day failed as specimens were in plastic state. 


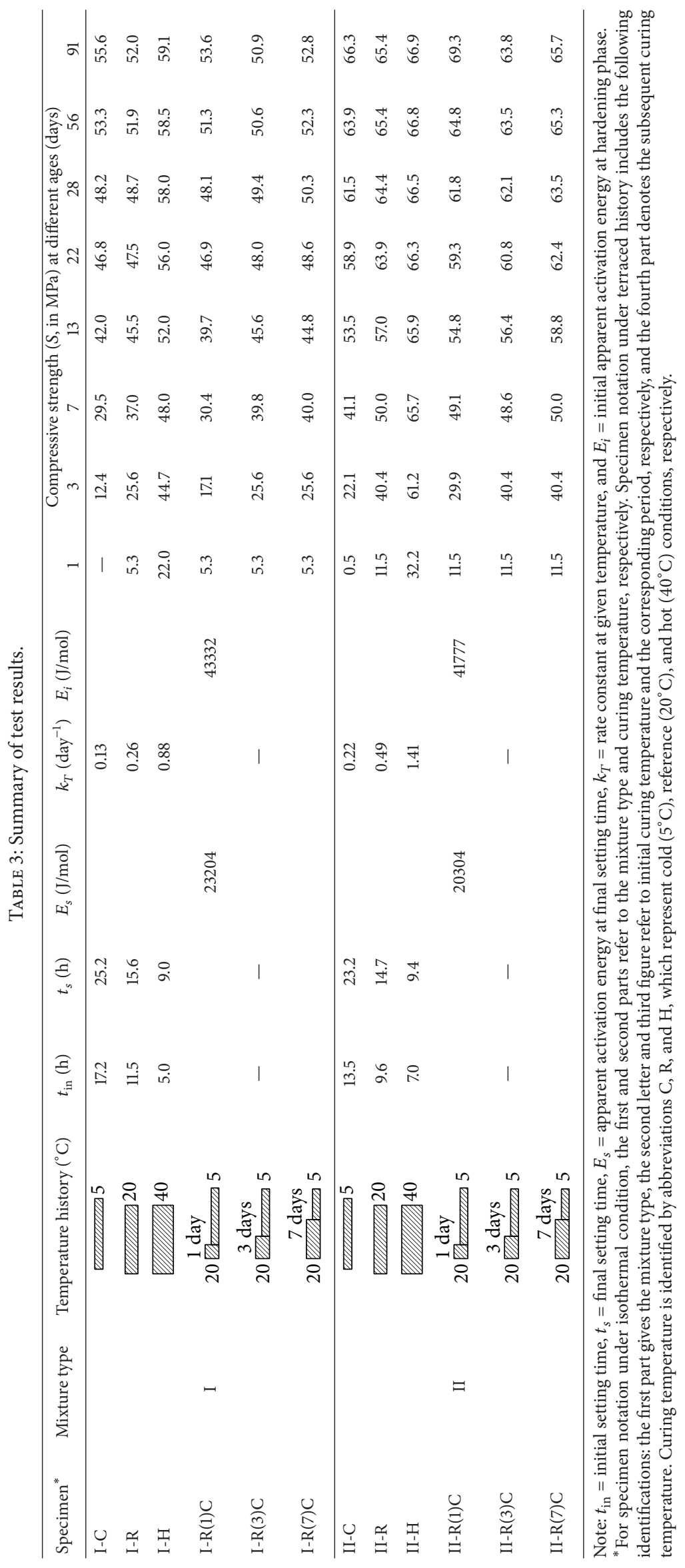




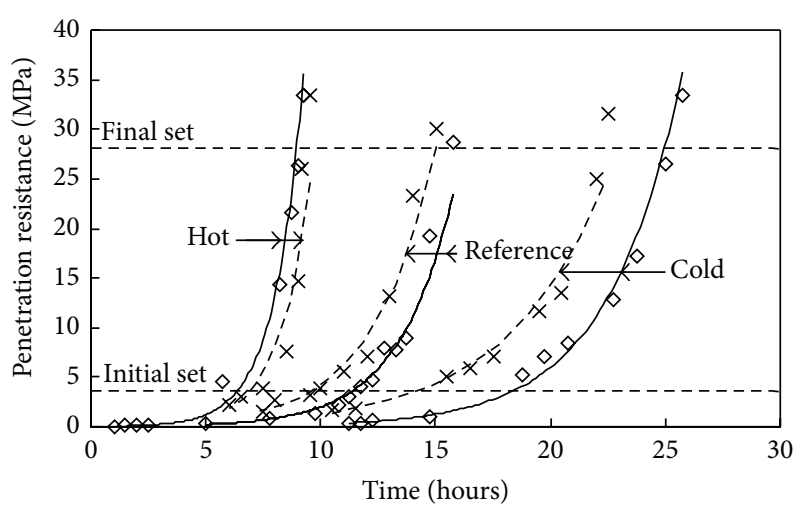

$\diamond$ Type I mixture

$\times$ Type II mixture

FIGURE 2: Setting behavior of concrete according to curing temperature.

\section{Test Results and Discussion}

Table 3 lists the values of key parameters required in the proposed maturity approach. The table also includes the test results for the average compressive strength obtained from three cylinders at each testing age. The present discussion focuses on the effect of $W / B$ on the apparent activation energies at setting and hardening phases and the compressive strength development of the concrete at various temperature histories to investigate the tendency of the maturity function in HSC.

4.1. Activation Energy until Final Setting Time. The general setting behavior of the two mixtures tested is plotted in Figure 2. The best-fit curves determined from each dataset are also shown in the figure. ASTM C 403 [14] defines initial and final set at penetration resistance of 3.4 and $27.6 \mathrm{MPa}$, respectively. The actual initial and final set times varied considerably with temperature, showing that the final set time for type I mixture was $25.2,15.6$, and $9.0 \mathrm{hrs}$ at curing temperature of 5,20 , and $40^{\circ} \mathrm{C}$, respectively. The initial and final settings occurred earlier with the increase in the initial curing temperature. A similar setting behavior in both mixtures was observed under the hot temperature condition, whereas the setting times under the reference and cold temperature conditions were lower in the type II mixture than in the type I mixture. The difference between the setting times according to $W / B$ decreased with increasing curing temperature. A lower $W / B$ reduces the water-filled spaces in the fresh paste, which results in quick establishment of the hydrated cement paste [23]. Thus, the concentration of $\mathrm{Ca}(\mathrm{OH})_{2}$ increases more quickly with the decrease in $W / B$. The accelerated chemical reactions of hydration owing to a rise in the curing temperature are faster with the decrease in the water-filled spaces in the paste.

The values of $E_{s}$ calculated from the Arrhenius plot using the inverse of final setting times were $23200 \mathrm{~J} / \mathrm{mol}$ for concrete with $W / B$ of 0.4 and $20300 \mathrm{~J} / \mathrm{mol}$ for concrete with $W / B$ of 0.28 . Tests conducted by Wade et al. [24] found $E_{s}$

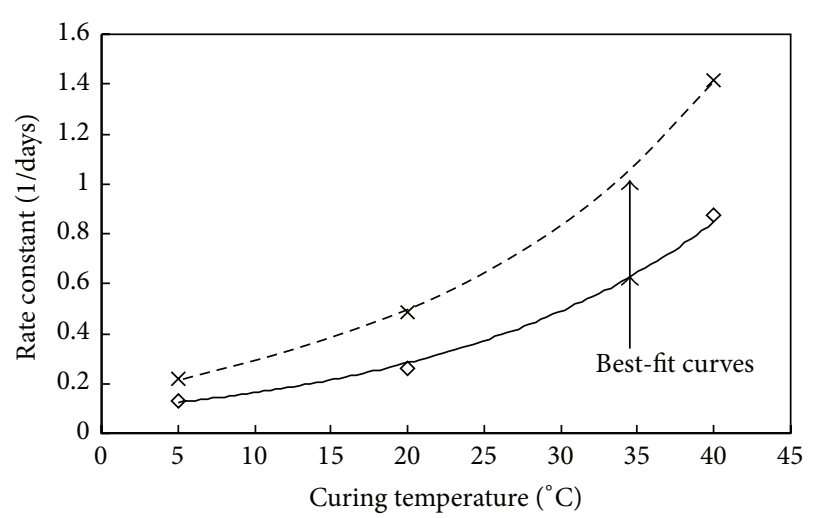

$\diamond$ Type I mixture

$\times$ Type II mixture

FIGURE 3: Rate constant at different curing temperatures.

values of OPC concrete to be $33400 \mathrm{~J} / \mathrm{mol}$ for $W / B$ of 0.48 and $27100 \mathrm{~J} / \mathrm{mol}$ for $W / B$ of 0.41 . Overall, $E_{s}$ tends to decrease with the decrease in $W / B$. For the curing temperature of 5 , 20 , and $40^{\circ} \mathrm{C}$, the equivalent ages until the final set time calculated using (8) were approximately 15.1, 15.6, and $16.5 \mathrm{hrs}$, respectively, for type I mixture and 13.9, 14.7, and $17.3 \mathrm{hrs,}$ respectively, for type II mixture. The equivalent ages until the final set time were more uniform than the actual time.

4.2. Initial Activation Energy at Hardening Phase. At the same curing temperature, the rate constant determined at the hardening phase was lower in the type I mixture than in the type II mixture, and these differences in both concrete mixtures decreased with decreasing curing temperature, as shown in Figure 3. For the cold temperature condition, the values of the rate constant were close in both concrete mixtures. This indicates that the influence of $W / B$ on the rate constant gradually decreases with decreasing curing temperature. On the other hand, the nature of the temperature dependence of the rate constant was similar in both concrete mixtures, showing a nonlinear variation with curing temperature. Consequently, the rate constant of HSC could be fitted using the exponential function of the curing temperature, as identified by the Arrhenius function.

The initial activation energy $\left(E_{i}\right)$ calculated from the Arrhenius plot of the natural logarithm of $k_{t}$ values versus temperatures was $43332 \mathrm{~J} / \mathrm{mol}$ for the type I mixture and $41777 \mathrm{~J} / \mathrm{mol}$ for the type II mixture. In general, values of $E_{i}$ for OPC concrete without SCMs have been reported [14] to be between 40000 and $45000 \mathrm{~J} / \mathrm{mol}$. The value of $E_{i}$ measured from the current concrete mixtures met the general range, indicating the decrease of $E_{i}$ with the decrease in $W / B$.

4.3. 28-Day Compressive Strength. Concrete produced using the type I mixture achieved the design strength of $42 \mathrm{MPa}$ at the age of 28 days regardless of curing history, whereas the 28day compressive strength of concrete of the type II mixture, except for concrete cured under the hot temperature condition, was slightly lower than the design strength of $65 \mathrm{MPa}$, 


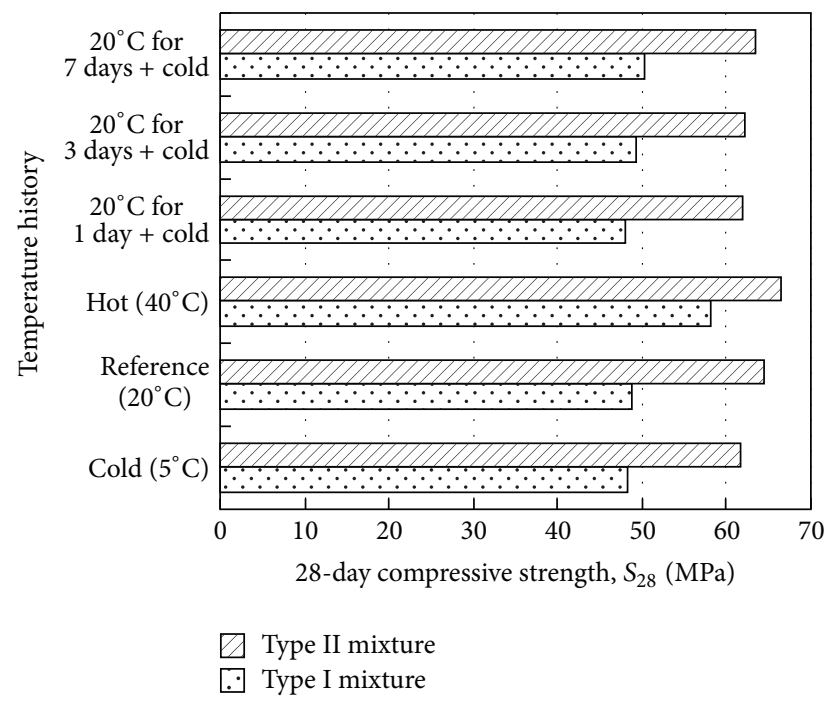

FIGURE 4: 28-day compressive strength according to temperature history.

as listed in Table 3. In general, a higher 28-day compressive strength was obtained in concrete cured under hot temperature condition than in the other concrete specimens under different temperature conditions, as shown in Figure 4. Compared to concrete cured at the reference temperature, concrete cured at the hot temperature developed a strength that was 1.19 times higher for type I and 1.03 times higher for type II, whereas concrete cured under the cold temperature showed 1-4.5\% lower strength. In general, the threshold age for the crossover effect is observed between 7 and 14 days in OPC concrete $[3,4,7,8]$. However, the present mixtures allowed a delayed threshold age after 91 days, revealing a lower 28-day strength under cold temperature. The chemical composition of the cement used for the present mixture was close to that of moderate heat cement, giving lower $\mathrm{C}_{3} \mathrm{~S}$ and $\mathrm{C}_{3} \mathrm{~A}$ contents than OPC. The reduced $\mathrm{C}_{3} \mathrm{~S}$ and $\mathrm{C}_{3} \mathrm{~A}$ contents in the modified cement were unfavorable to the strength development at an early age and under cold curing temperature.

It is also interesting that close values of 28-day strength were observed between concrete specimens cured under cold temperature condition and those cured at $20^{\circ} \mathrm{C}$ for an age of 1 day and subsequent cold temperature. These close values were also observed between concrete specimens cured at the reference temperature and those cured at $20^{\circ} \mathrm{C}$ for an age of 3 days or 7 days and subsequent cold temperatures. In general, the decrease in $W / B$ allows faster hydration rate of cement paste, which results in higher strength development and greater sensitivity to curing temperature at an early age. Therefore, the early age of 3 days can be regarded as a critical period in terms of the influence of the early curing temperature histories on the 28-day compressive strength gain of HSC.

4.4. Relative Compressive Strength Development. The ratio of compressive strength development at various ages relative to 28-day strength is plotted in Figure 5. Concrete specimens cured under the isothermal cold condition developed a lower early strength than those at the hot and the reference temperature conditions, whereas the highest strength gain rate was observed in concrete cured under the isothermal cold condition at the long-term age after 28 days. Therefore, crossover effect could be identified in concrete specimens cured under the isothermal condition, although an absolute strength of concrete cured under hot temperature was commonly higher than that of concrete under cold temperature because of lower $\mathrm{C}_{3} \mathrm{~S}$ and $\mathrm{C}_{3} \mathrm{~A}$ contents in the modified cement. For the type I mixture, the strength gain rate at the age of 3 days at the hot temperature was approximately double that in the companion concrete at the cold temperature. These differences according to curing temperature decreased gradually up to the age of 28 days, beyond which the strength gain rate of concrete at the cold temperature was 1.1 times higher than that of the companion concrete at the hot temperature. Under the hot temperature, the early-strength development of the type I concrete was higher than that of the type II concrete, showing a constant strength gain after the age of 7 days. The longterm strength development under the hot temperature was only 1.04 times higher in the type I concrete than in the type II concrete. Overall, the crossover effect was alleviated with decreasing $W / B$.

Concrete cured at terrace-shaped variable temperature histories showed a similar strength gain rate regardless of the reference temperature period at an early age, although a slightly more evident crossover effect was observed in concrete at the reference temperature for the first day and the subsequent cold temperature than in concrete specimens at other histories. In all concrete specimens cured at variable temperature histories, except specimen IR(1)C, strength gain of approximately $80 \%$ was achieved within the first 7 days. In constructing nuclear facility structures under a severe freezethaw environment, the formwork for normally hardening concrete must be retained until $80 \%$ of the design strength of the concrete is achieved. Considering this requirement, concrete produced using the present mixture proportions should ideally be cured at $20^{\circ} \mathrm{C}$ for a minimum of the first 3 days to facilitate removal of the formwork and shoring within 7 days. Furthermore, the variable curing temperature regimes indicate that concrete strength gain rate is independent of the subsequent cold curing temperature history once the concrete is cured at the reference temperature for the first 3 days.

\section{Verification of the Proposed Maturity Approach}

The compressive strength development of concrete using the present mixture proportions was predicted on the basis of the proposed maturity approach. For the application of the relative strength-maturity relationship, the values of key parameters $\left(t_{s r}, k_{r}, E_{i}\right.$, and $\left.E_{s}\right)$ listed in Table 1 were used for each concrete specimen, independent of the curing temperature histories. To calculate the compressive strength at a given age from the relative strength ratio, the relationship between $S_{28}$ and $\left(S_{28}\right)_{T_{r}}$ was also empirically formulated using the current test data. The relationship between $S_{28}$ and $\left(S_{28}\right)_{T_{r}}$ 

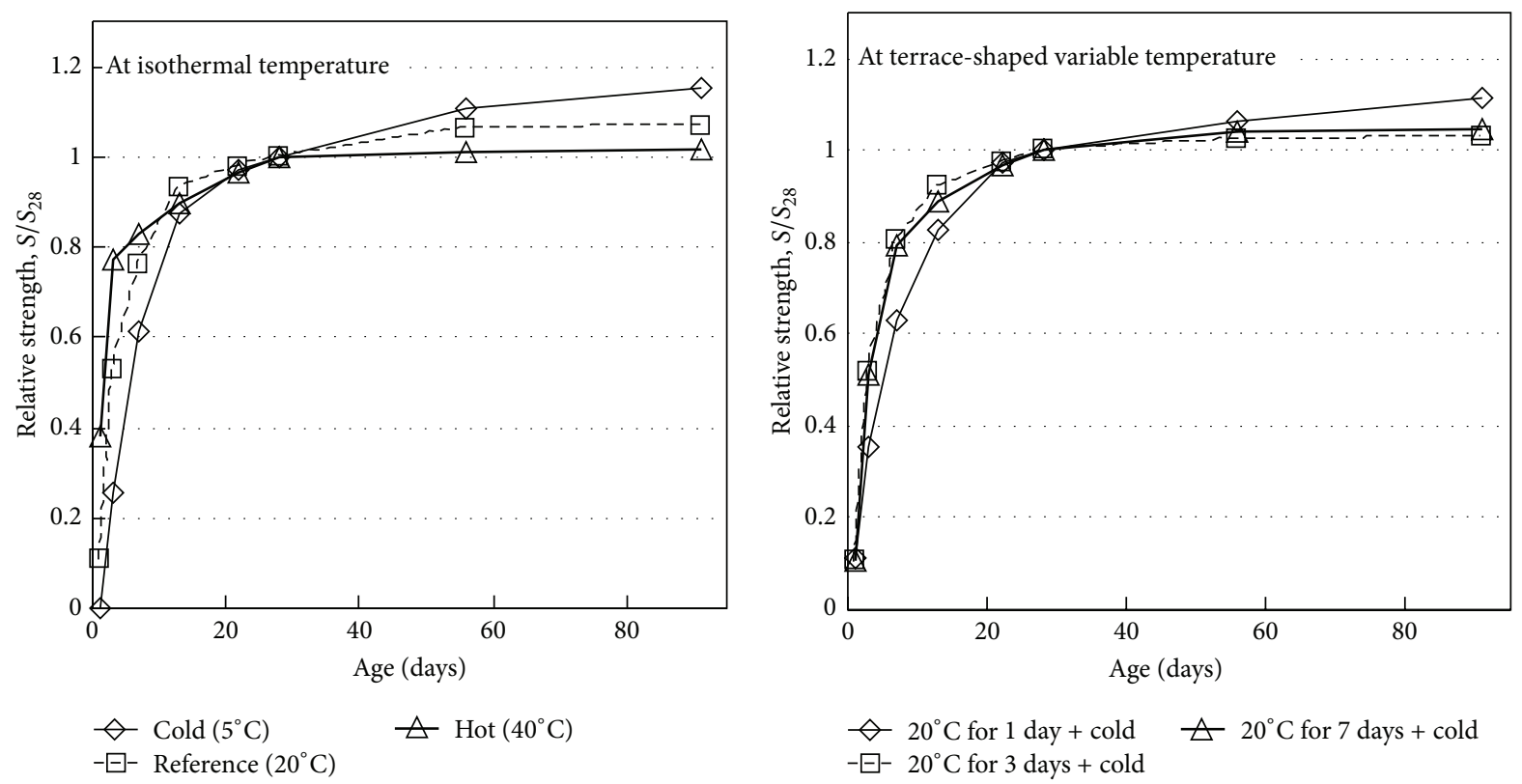

(a)
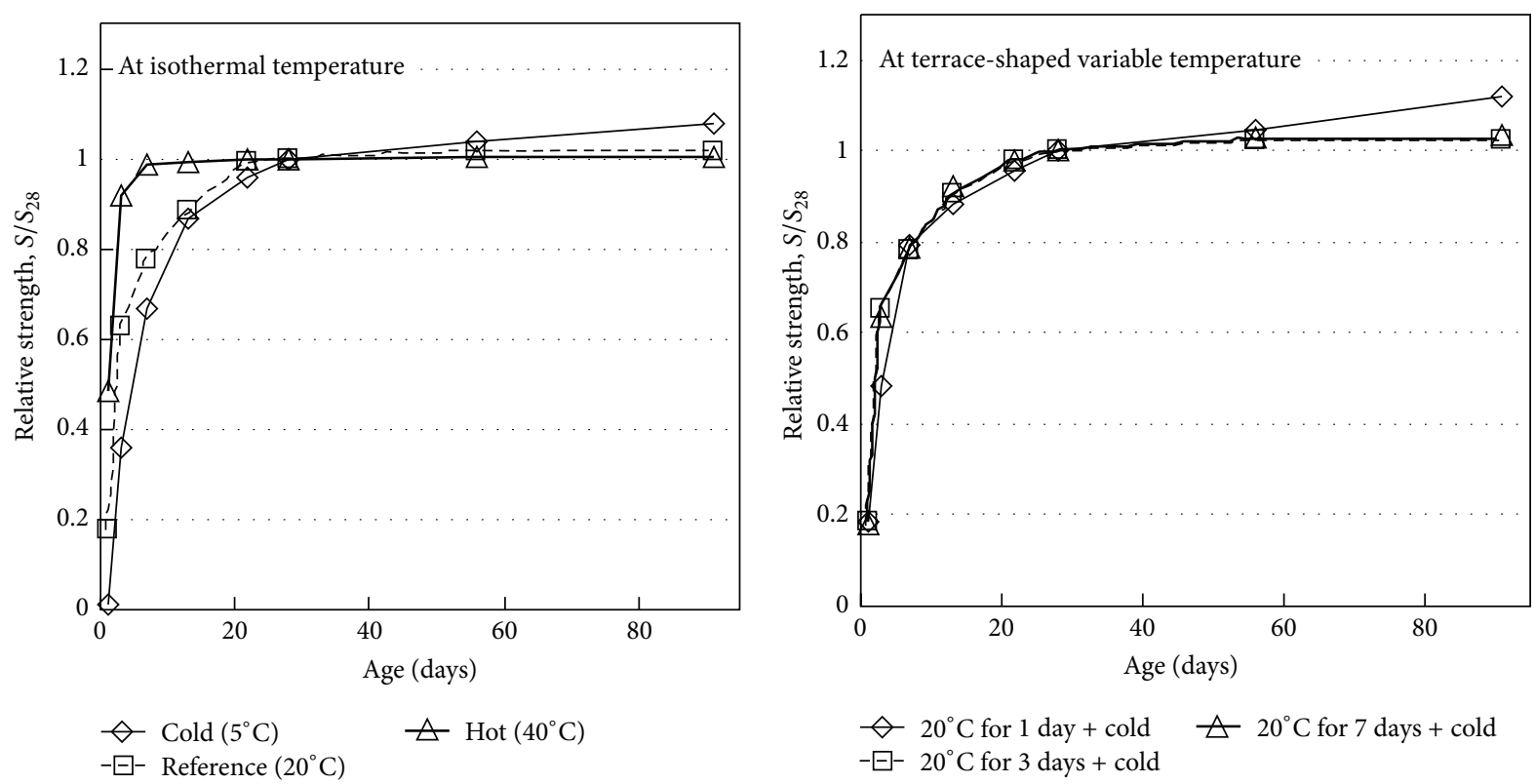

(b)

FIGURE 5: Relative strength development according to temperature history: (a) type I mixture and (b) type II mixture.

was significantly affected by $W / B$ and the curing temperature history. In particular, the temperature until the early age of 3 days could be regarded as a critical factor to represent the whole temperature history, as shown in Figures 4 and 5. Based on regression analysis using these two influencing parameters, the following relationship between $S_{28}$ and $\left(S_{28}\right)_{T_{r}}$ can be obtained (Figure 6):

$$
S_{28}=\left[1.5\left(\frac{T_{A 3}}{T_{r}}\right)^{2.5}(W / B)^{4}+0.97\right]\left(S_{28}\right)_{T_{r}},
$$

where $T_{A 3}$ is the average temperature until the age of 3 days.
5.1. Relative Strength-Maturity Relationship. The relative strength-maturity relationship measured from the type I concrete is compared with predictions obtained using (4) (see Figure 7). The relative strength-maturity relationship was insignificantly influenced by the early curing period at the reference temperature. For the isothermal curing condition, the proposed maturity approach provides a comparatively high accuracy in predicting the relative strength development of HSC, although the approach tends to underestimate slightly the early strength of concrete at cold temperature. In contrast, predictions for the relative strength development of concrete at variable temperature histories are commonly lower than 
TABle 4: Standard deviation of absolute error determined from measured strength and predictions using the modified equivalent age.

\begin{tabular}{|c|c|c|c|c|c|c|c|c|c|}
\hline \multirow{2}{*}{$\begin{array}{l}\text { Concrete } \\
\text { type }\end{array}$} & \multicolumn{8}{|c|}{ Age (days) } & \multirow{2}{*}{ Total } \\
\hline & 1 & 3 & 7 & 13 & 22 & 28 & 56 & 91 & \\
\hline I & $\begin{array}{c}0.93 \\
(0.041)\end{array}$ & $\begin{array}{c}4.09 \\
(0.040)\end{array}$ & $\begin{array}{c}4.78 \\
(0.090)\end{array}$ & $\begin{array}{c}4.34 \\
(0.077)\end{array}$ & $\begin{array}{c}2.17 \\
(0.037)\end{array}$ & $\begin{array}{c}1.01 \\
(0.015)\end{array}$ & $\begin{array}{c}1.59 \\
(0.019)\end{array}$ & $\begin{array}{c}2.35 \\
(0.018)\end{array}$ & $\begin{array}{c}2.81 \\
(0.084)\end{array}$ \\
\hline II & $\begin{array}{c}0.80 \\
(0.057)\end{array}$ & $\begin{array}{c}4.77 \\
(0.027)\end{array}$ & $\begin{array}{c}3.91 \\
(0.076)\end{array}$ & $\begin{array}{c}1.59 \\
(0.027)\end{array}$ & $\begin{array}{c}1.41 \\
(0.019)\end{array}$ & $\begin{array}{c}0.89 \\
(0.014)\end{array}$ & $\begin{array}{c}1.45 \\
(0.024)\end{array}$ & $\begin{array}{c}1.97 \\
(0.018)\end{array}$ & $\begin{array}{c}2.33 \\
(0.052)\end{array}$ \\
\hline
\end{tabular}

Note: figures in parenthesis refer to the coefficient of variance of the ratios between measured and predicted strengths.

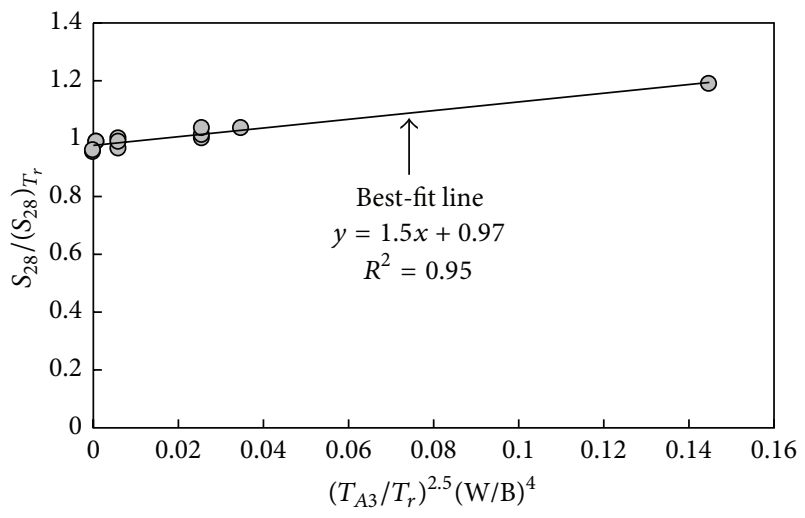

FIGURE 6: Regression analysis for relation of $S_{28}$ and $\left(S_{28}\right)_{T_{r}}$.

those obtained in tests at an early age, but higher than those obtained in the test results after an age of 28 days (an equivalent age of approximately 13 days). The differences between measured and predicted values after an age of 28 days gradually increase with age. The residue of the waterfilled spaces in the fresh paste, called capillary pores, depends on the $W / B$ and the degree of hydration. Free water held in capillaries delays the hydration process of paste. Thus, a lower $W / B$ is favorable to production of a solution supersaturated with $\mathrm{Ca}(\mathrm{OH})_{2}$ and containing concentrations of calcium silicate hydrate in a metastable condition [23]. The subsequent hardening is due to the withdrawal of water from the hydrated material. This hydration process of cement paste is rapider with increasing curing temperature because of the accelerated evaporation of free water. Overall, HSC becomes more sensitive to early curing temperature than NSC.

The strength development of HSC is independent of the curing temperature after an early critical age. Considering this early-age curing temperature effect and that the first 3 days are a critical period, the equivalent age of (9) can be modified for HSC as follows:

$$
\begin{aligned}
t_{e}= & \sum_{0}^{t_{s r}} \exp \left[\frac{-E_{s}}{R}\left(\frac{1}{T+273}-\frac{1}{T_{r}+273}\right)\right] \Delta t \\
& +\sum_{t_{s r}}^{3} \exp \left[\frac{-E_{a}}{R}\left(\frac{1}{T+273}-\frac{1}{T_{r}+273}\right)\right] \Delta t \\
& +\sum_{3}^{t} \exp \left[\frac{-E_{a}}{R}\left(\frac{1}{T_{A 3}+273}-\frac{1}{T_{r}+273}\right)\right] \Delta t .
\end{aligned}
$$

The relative strength of concrete specimens cured at variable temperature history is compared with the maturity approach using the modified equivalent age given above (see Figure 8). Compared with Figure 7(b), the predictions using the modified equivalent age are in better agreement with the test results, even at the long-term age. The differences between predictions and measured relative strength values are similar for both concrete types. It should be noted that (12) needs to be further examined for concrete cured at variable history with hot or cold temperature during early age.

5.2. Strength Development at Different Ages. Comparisons of measured concrete compressive strength at different ages and the predictions are shown in Figure 9. In the predictions using the proposed maturity approach, the 28 -day strength and equivalent age of each concrete specimen are determined from (11) and (12), respectively. For an unbiased statistical evaluation, the following standard deviation $\left(\gamma_{s}\right)$ of the absolute error was calculated for each age (see Table 4):

$$
\gamma_{s}=\sqrt{\frac{1}{n-1} \sum_{i}^{n}\left[\left(S_{i}\right)_{\mathrm{Exp}}-\left(S_{i}\right)_{\mathrm{Pre}}\right]^{2}},
$$

where $n$ is the number of data points and $\left(S_{i}\right)_{\text {Exp. }}$ and $\left(S_{i}\right)_{\text {Pre. }}$ are the measured and predicted compressive strengths, respectively, at age $i$ of each specimen. In general, the proposed maturity approach tended to underestimate the early strength until the age of 7 days for the type I concrete regardless of the curing temperature regimes. For the type II concrete, the largest scatter was observed at the age of 3 days. Consequently, the highest value of $\gamma_{s}$ was estimated to be $4.78 \mathrm{MPa}$ at the age of 3 days for the type I concrete and $4.77 \mathrm{MPa}$ at the age of 7 days for the type II concrete. After the age of 22 days, the scatter band diminished, giving values of $\gamma_{s}$ below 2.17 MPa for the type I mixture and 1.41 MPa for the type II mixture. Overall, $\gamma_{s}$ determined from all tested ages and curing temperature regimes was $2.81 \mathrm{MPa}$ for the type I concrete and $2.32 \mathrm{MPa}$ for the type II concrete. Compared with design strength of concrete, these values correspond to approximately $6.7 \%$ for the type I mixture and $3.6 \%$ for the type II mixture. In addition, the coefficient of variance of the ratios between measured and predicted strengths at different ages ranged from 0.015 to 0.090 . Therefore, the proposed maturity approach with the modified equivalent age appears 

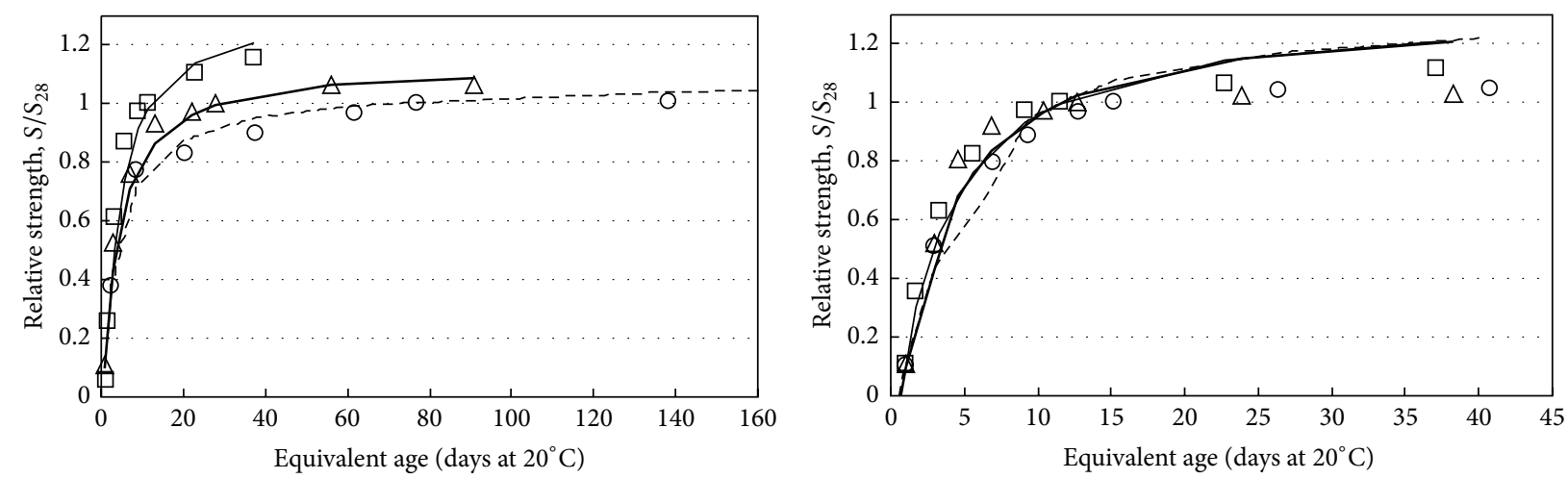

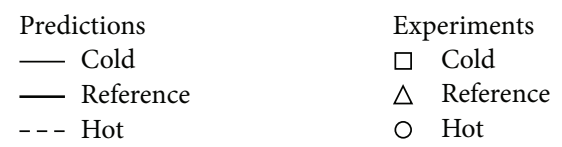

(a)

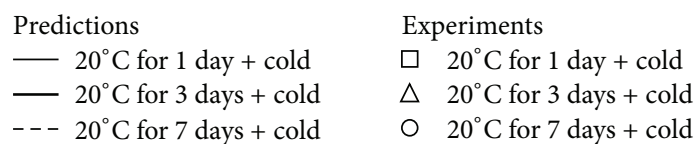

(b)

FIGURE 7: Comparisons of measured relative strength-maturity relationship and prediction (type I mixture): (a) at isothermal temperature and (b) at terrace-shaped variable temperature.

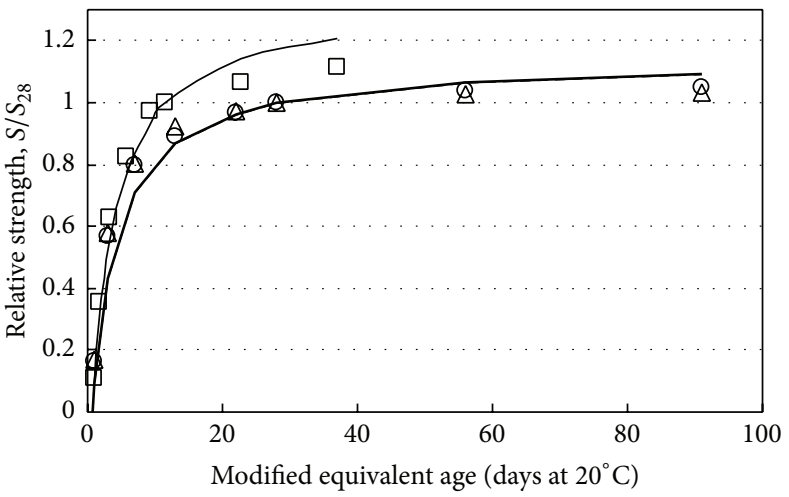

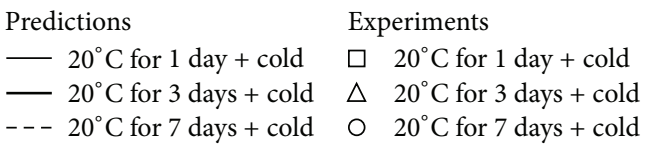

(a)

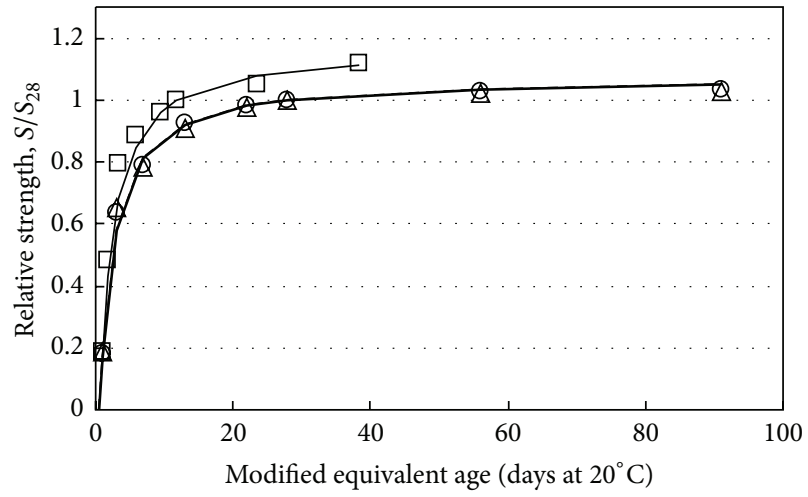

Predictions

$-20^{\circ} \mathrm{C}$ for 1 day + cold
$-20^{\circ} \mathrm{C}$ for 3 days + cold
$---20^{\circ} \mathrm{C}$ for 7 days + cold

Experiments

$\square \quad 20^{\circ} \mathrm{C}$ for 1 day + cold

$\triangle 20^{\circ} \mathrm{C}$ for 3 days + cold

O $20^{\circ} \mathrm{C}$ for 7 days + cold

(b)

Figure 8: Comparisons of experiments and relative strength-maturity relationship predicted using the modified equivalent age at variable temperature history: (a) type I mixture and (b) type II mixture.

to be useful as an alternative tool for practical evaluation of the in-place strength development of HSC at various curing temperature histories.

\section{Conclusions}

On the basis of the test results, the traditional maturity function of an equivalent age was modified to consider the offset maturity and the insignificance of subsequent curing temperature after an age of 3 days on later strength of concrete. However, the proposed equations, particularly the modified equivalent age, need to be investigated further for different mixture proportions with SCMs and various temperature regimes with initial hot or cold temperature and another subsequent temperature. From the investigation of the strength development of HSC based on the proposed maturity approach, the following conclusions may be drawn:

(1) With decreasing water-to-binder ratio $(W / B)$, the apparent activation energy at the setting and hardening phases tended to decrease.

(2) Compared to concrete cured at the reference temperature $\left(20^{\circ} \mathrm{C}\right)$, concrete at the hot temperature $\left(40^{\circ} \mathrm{C}\right)$ developed a strength that was 1.19 times higher for the type I mixture with $W / B$ of 0.4 and 1.03 times higher for the type II mixture with $W / B$ of 0.28 , whereas 


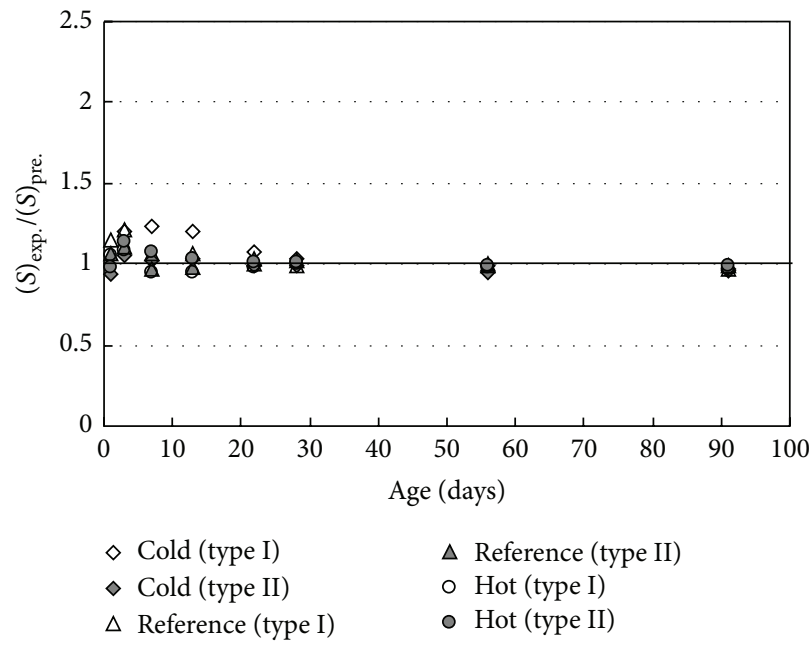

(a)

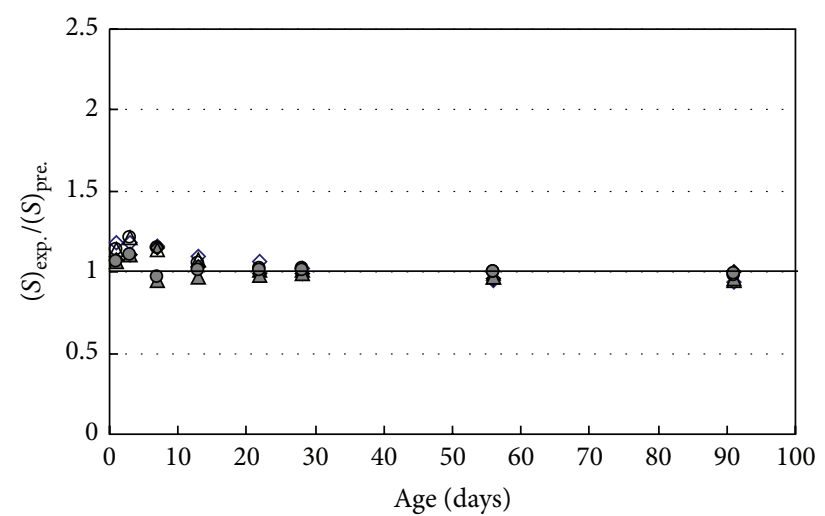

$\diamond 20^{\circ} \mathrm{C}$ for 1 day + cold (type I) $\quad \Delta \quad 20^{\circ} \mathrm{C}$ for 3 days + cold (type II)

$\diamond 20^{\circ} \mathrm{C}$ for 1 day + cold (type II) $\quad 20^{\circ} \mathrm{C}$ for 7 days + cold (type I)

$\triangle 20^{\circ} \mathrm{C}$ for 3 days + cold (type I) $\circ 20^{\circ} \mathrm{C}$ for 7 days + cold (type II)

(b)

Figure 9: Comparisons of measured strength and prediction using the modified equivalent age: (a) at isothermal temperature and (b) at terrace-shaped variable temperature.

concrete at the cold temperature $\left(5^{\circ} \mathrm{C}\right)$ showed $1.0-$ $4.5 \%$ lower strength development.

(3) Similar strength development was achieved for concrete specimens at the isothermal reference temperature and those cured at the variable history of the reference temperature for initial age of 3 days or 7 days and subsequent cold temperature.

(4) The crossover effect on relative strength development was slightly alleviated with decreasing $W / B$.

(5) The setting time and strength development were more sensitive to early curing temperature with decreasing $W / B$.

(6) The proposed maturity approach with the modified equivalent age accurately predicts the strength development of HSC according to age, indicating the value of the standard deviation of the absolute error of 2.81 MPa for the type I concrete and 2.32 MPa for the type II concrete.

\section{Notations}

A: Experimental constant $\left(\right.$ day $\left.^{-1}\right)$

$E_{a}:$ Apparent activation energy $(\mathrm{J} / \mathrm{mol})$

$E_{s}$ : Apparent activation energy until final setting time $(\mathrm{J} / \mathrm{mol})$

$E_{i}$ : Initial apparent activation energy at the hardening phase $(\mathrm{J} / \mathrm{mol})$

$k_{T}$ : Rate constant $\left(\right.$ day $\left.^{-1}\right)$ for strength development at the curing temperature

$k_{s r}:$ Rate constants $\left(\right.$ day $\left.^{-1}\right)$ for the setting development at the reference temperature

$k_{\text {sT }}$ : Rate constants $\left(\mathrm{day}^{-1}\right)$ for the setting development at the curing temperature $k_{r}$ : Rate constant $\left(\right.$ day $\left.^{-1}\right)$ at the reference temperature

$R: \quad$ Universal gas constant $(=8.314 \mathrm{~J} / \mathrm{mol} \cdot \mathrm{K})$

$S: \quad$ Compressive strength $(\mathrm{MPa})$

$S_{u}: \quad$ Limiting strength $(\mathrm{MPa})$

$S_{28}: \quad$ 28-day compressive strength (MPa)

$\left(S_{28}\right)_{T_{r}}$ : 28-day compressive strength of concrete cured at the reference temperature (MPa)

$T: \quad$ Curing temperature $\left({ }^{\circ} \mathrm{C}\right)$

$T_{r}: \quad$ Reference temperature $\left(=20^{\circ} \mathrm{C}\right)$

$t: \quad$ Age (days)

$t_{e}: \quad$ Equivalent age (days)

$t_{\mathrm{eh}}: \quad$ Equivalent age at hardening phase (days)

$t_{0}$ : $\quad$ Offset time (days)

$t_{0 r}$ : Offset time (days) at the reference temperature

$t_{s r}: \quad$ Final setting time (days) of concrete at the reference temperature

$t_{s}: \quad$ Final setting time (days)

$W / B$ : Water-to-binder ratio by weight

$\beta_{1}$ : $\quad$ Limiting strength-to-28-day strength ratio

$\gamma$ : $\quad$ Affinity ratio of the rate constants at the hardening phase.

\section{Conflict of Interests}

The authors declare that there is no conflict of interests regarding the publication of this paper.

\section{Acknowledgment}

This work was supported by the Nuclear Power R\&D Program of the Korea Institute of Energy Technology Evaluation and Planning (KETEP), grant funded by the Korea Government Ministry of Knowledge Economy (no. 2011T100200161). 


\section{References}

[1] ACI-ASCE Committee 441, "High-strength concrete columns: state of the art," ACI Structural Journal, vol. 94, no. 3, pp. 323335, 1997.

[2] S. J. Barnett, M. N. Soutsos, J. H. Bungey, and S. G. Millard, "Fast-track construction with slag cement concrete: adiabatic strength development and strength prediction," ACI Materials Journal, vol. 104, no. 4, pp. 388-396, 2007.

[3] N. J. Carino and R. C. Tank, "Maturity functions for concretes made with various cements and admixtures," ACI Materials Journal, vol. 89, no. 2, pp. 188-196, 1992.

[4] C. Vázquez-Herrero, I. Martínez-Lage, and F. SánchezTembleque, "A new procedure to ensure structural safety based on the maturity method and limit state theory," Construction and Building Materials, vol. 35, pp. 393-398, 2012.

[5] K. O. Kjellsen and R. J. Detwiler, "Later-age strength prediction by a modified maturity model," ACI Materials Journal, vol. 90, no. 3, pp. 220-227, 1993.

[6] G. Chanvillard and L. D'Aloia, "Concrete strength estimation at early ages: modification of the method of equivalent age," ACI Materials Journal, vol. 94, no. 6, pp. 520-530, 1997.

[7] Y. A. Abdel-Jawad, "The maturity method: modifications to improve estimation of concrete strength at later ages," Construction and Building Materials, vol. 20, no. 10, pp. 893-900, 2006.

[8] C. F. Kee, "Relation between strength and maturity of concrete," ACI Journal, vol. 68, no. 3, pp. 196-203, 1971.

[9] J.-K. Kim, Y.-H. Moon, and S.-H. Eo, “Compressive strength development of concrete with different curing time and temperature," Cement and Concrete Research, vol. 28, no. 12, pp. 17611773, 1998.

[10] W.-C. Liao, B. J. Lee, and C. W. Kang, "A humidity-adjusted maturity function for the early age strength prediction of concrete," Cement and Concrete Composites, vol. 30, no. 6, pp. 515-523, 2008.

[11] S. H. Kwon, K. P. Jang, J.-W. Bang, J. H. Lee, and Y. Y. Kim, "Prediction of concrete compressive strength considering humidity and temperature in the construction of nuclear power plants," Nuclear Engineering and Design, vol. 275, pp. 23-29, 2014.

[12] J. Zhang, D. Cusson, P. Monteiro, and J. Harvey, "New perspectives on maturity method and approach for high performance concrete applications," Cement and Concrete Research, vol. 38, no. 12, pp. 1438-1446, 2008.

[13] P. F. Hansen and E. J. Pedersen, "Maturity computer for controlled curing and hardening of concrete," Swedish National Road and Transport Research Institute, vol. 1, pp. 21-25, 1977.

[14] ASTM C1074- C403, Annual Book of ASTM Standards: V. 4.02, ASTM International, 2011.

[15] R. C. A. Pinto and A. K. Schindler, "Unified modeling of setting and strength development," Cement and Concrete Research, vol. 40, no. 1, pp. 58-65, 2010.

[16] R. C. A. Pinto and K. C. Hover, "Application of maturity approach to setting times," ACI Materials Journal, vol. 96, no. 6, pp. 686-691, 1999.

[17] S. W. Cha, Modeling of hydration process and analysis of thermal and hygral stresses in hardening concrete [Ph.D. thesis], Seoul National University, Seoul, Republic of Korea, 1999.

[18] J. Byfors, Plain Concrete at Early Ages, vol. 80 of CBI Research Report no. 3, Swedish Cement and Concrete Research Institute, 1980.
[19] J. K. Kim, S. H. Hun Han, and S. K. Kyun Park, "Effect of temperature and aging on the mechanical properties of concrete: part II. Prediction model," Cement and Concrete Research, vol. 32, no. 7, pp. 1095-1100, 2002.

[20] E. H. Kadri, S. Aggoun, S. Kenai, and A. Kaci, "The compressive strength of high-performance concrete and ultrahighperformance," Advances in Materials Science and Engineering, vol. 2012, Article ID 361857, 7 pages, 2012.

[21] H.-S. Shang, T.-H. Yi, and L.-S. Yang, "Experimental study on the compressive strength of big mobility concrete with nondestructive testing method," Advances in Materials Science and Engineering, vol. 2012, Article ID 345214, 6 pages, 2012.

[22] Y. Jiao, H. Liu, X. Wang, Y. Zhang, G. Luo, and Y. Gong, "Temperature effect on mechanical properties and damage identification of concrete structure," Advances in Materials Science and Engineering, vol. 2014, Article ID 191360, 10 pages, 2014.

[23] A. M. Neville, Properties of Concrete, Addison Wesley Longman, New York, NY, USA, 1995.

[24] S. A. Wade, J. M. Nixon, A. K. Schindler, and R. W. Barnes, "Effect of temperature on the setting behavior of concrete," ASCE Journal of Materials in Civil Engineering, vol. 22, no. 3, Article ID 002003QMT, pp. 214-222, 2010. 

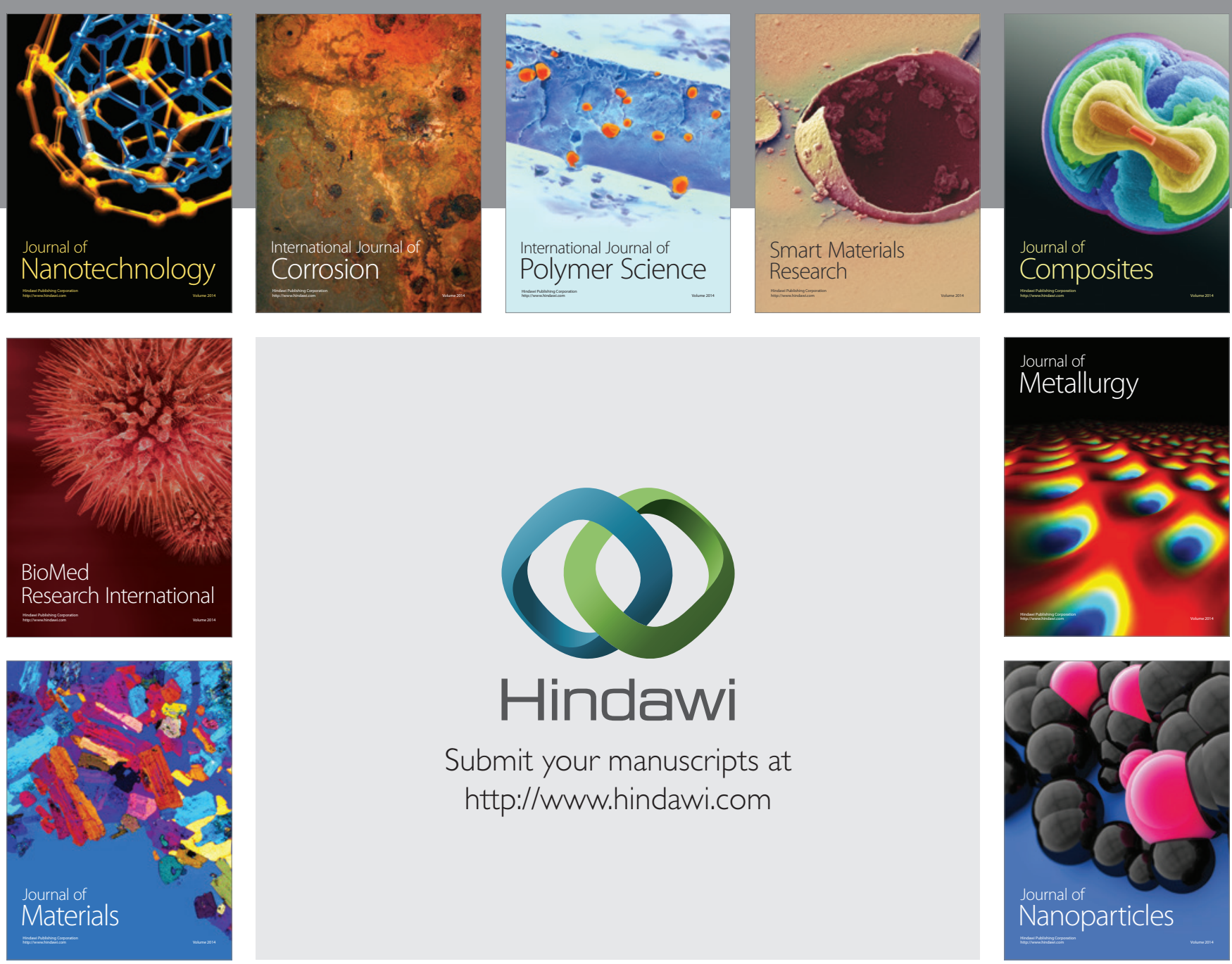

Submit your manuscripts at http://www.hindawi.com
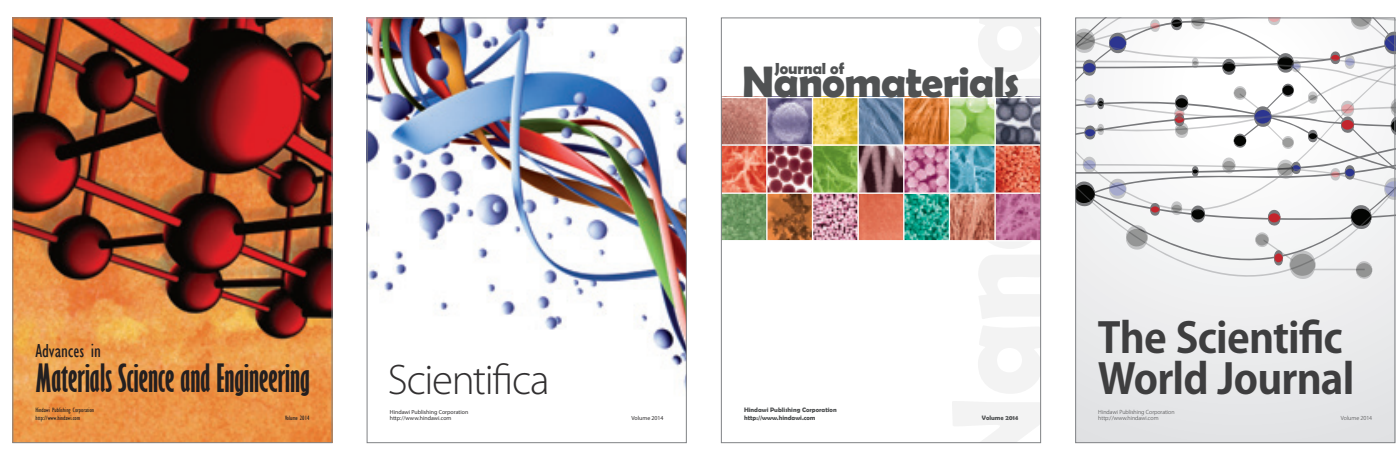

\section{The Scientific World Journal}
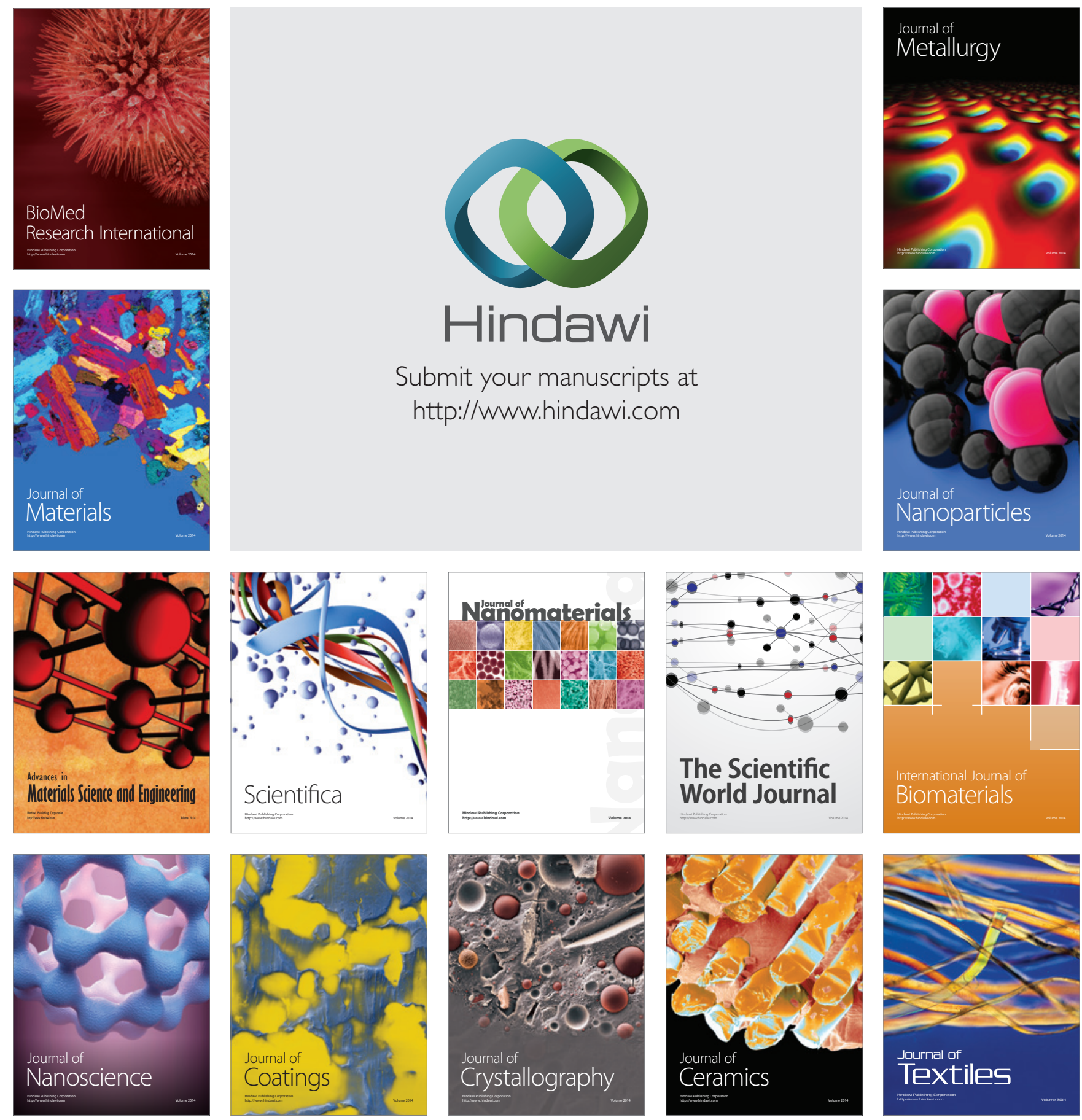